\title{
Design of Yagi-Uda Antenna using Microstrip Circuit
}

\author{
Payal \\ Dept. of Electronics and Comm. \\ Lovely Professional University \\ Phagwara, India
}

\author{
R. Madhusudhan Goud \\ Assistant Professor \\ Lovely Professional University \\ Phagwara, India
}

\author{
Komalpreet Kaur \\ Dept. of Electronics and Comm. \\ Lovely Professional University \\ Phagwara, India
}

\begin{abstract}
This paper gives the design of Yagi-Uda antenna using microstrip circuit. Microstip circuits are used to implement Yagi-Uda antenna so as to reduce the size but here we have shown only two optimization technique. This has been done by varying the length, width and spacing between reflector, driven element and directors. Simulations are conducted to show how return loss and other parameters vary by varying the above mentioned Yagi-Uda parameters. This antenna is operating very near to resonant frequency $\mathrm{fr}=2.4 \mathrm{GHz}$ with the specification relative permittivity $\varepsilon_{\mathrm{r}}=3.2$, height of substrate $\mathrm{h}=1.6 \mathrm{~mm}$, characteristic impedance $\mathrm{Z}_{0}=50 \mathrm{ohm}$ and thickness of strip conductor $t=35 \mathrm{um}$. In this paper, two most approximate results after all these perturbations are analyzed and simulations showing return loss and other parameters like directivity, gain and power radiated are discussed. The simulation process has been done using Advanced Design System (ADS) tool.
\end{abstract}

\section{General Terms}

Advanced Design System (ADS), Microstrip circuit, YagiUda Antenna

\section{Keywords}

Microstrip circuit, Reflector, driven element, Directors, inset fed, S-Parameters.

\section{INTRODUCTION}

Yagi-Uda antenna is a practical radiator in the $\mathrm{HF}(3-30 \mathrm{MHz})$, VHF $(30-300 \mathrm{MHz})$ and UHF $(300-3000 \mathrm{MHz})$. Yagi -Uda antenna using microstrip circuits is a very demanding structure in the $4 \mathrm{G}$ cellular applications. Using microstrip circuits, size of Yagi-Uda antenna can be designed in $\mathrm{mm}$ dimension as compared to the Yagi-Uda design formed from large conducting wires. Microstrip circuit Yagi-Uda antennas are quite common in practice because they are lightweight, simple to build, low-cost and provide moderately desirable characteristics (including a unidirectional beam) for many applications. Yagi-Uda antenna system has the different elements such as reflector, driven element, and a row of directors. For a specific design, these element's lengths and spacing between them is of great importance. The reflector's length is greater than that of driven element and spacing between them is $0.25 \lambda$ whereas director's length is less than the driven element's length and spacing between them is more than $0.25 \lambda$ [4].

Apart from Yagi-Uda structure, microstrip circuits used in this design are of great importance. In the two optimized designs discussed in this paper, three and two directors are used respectively.

\section{MICROSTRIP CIRCUITS}

The design of this Yagi-Uda is based on microstrip circuit. It consists of a thin conducting strip of width $\mathrm{W}$ is placed on grounded dielectric substrate of thickness $d$ and relative permittivity $\varepsilon_{\mathrm{r}}$ [5]. but for the design of this $\mathrm{mm}$ dimension antenna we have used the line calc of ADS tool which directly gives the width and length of design on the basis of parameter $h, \varepsilon_{\mathrm{r}}, \mathrm{t}, \mathrm{Z}_{0}$ and $\mathrm{f}_{\mathrm{r}}$ provided and $\mathrm{E}_{\text {eff }}$ is calculated using the equation (1). This analysis is shown in figure 1 .

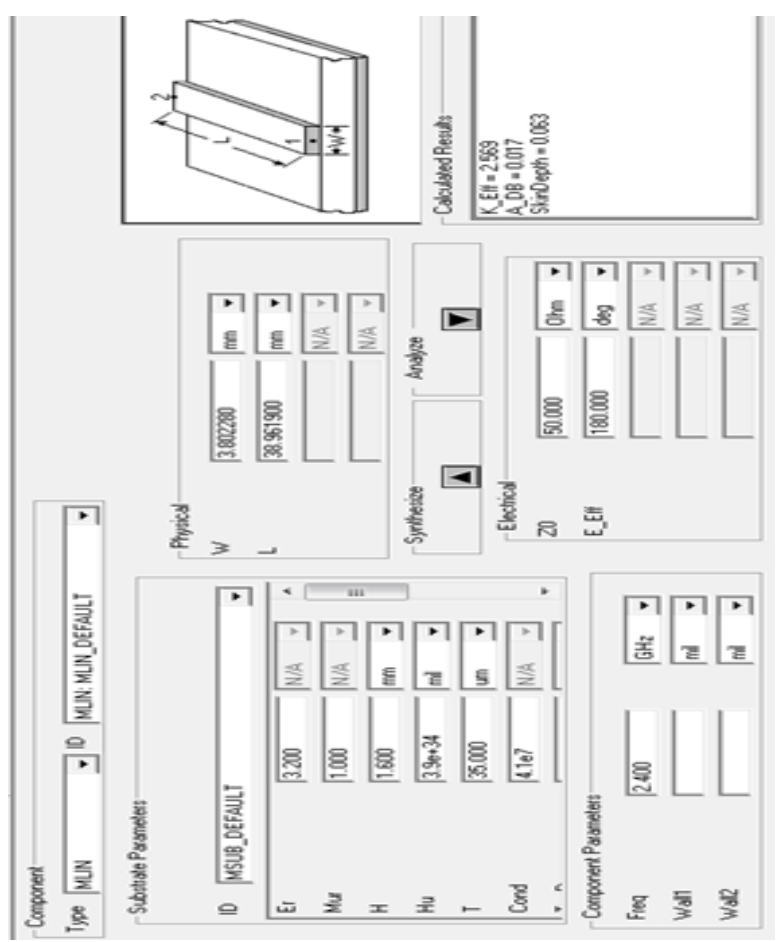

Figure 1. line calc

Without using line calc of ADS tool we can directly find the dimension using the formulas given below [5]:

(1) The effective dielectric constant of a microstrip line is given approximately by

$$
\epsilon_{e}=\frac{\epsilon_{r}+1}{2}+\frac{\epsilon_{r}-1}{2} \frac{1}{\sqrt{1+12 d / W}}
$$


(3) Given the dimensions of the microstrip line, the characteristic impedance can be calculated as

$$
Z_{0}= \begin{cases}\frac{60}{\sqrt{\epsilon_{e}} \ln \left(\frac{8 d}{W}+\frac{W}{4 d}\right)} & \text { for } W / d \leq 1 \\ \frac{120 \pi}{\sqrt{\epsilon_{e}}[W / d+1.393+0.667 \ln (W / d+1.444)]} & \text { for } W / d \geq 1 .\end{cases}
$$

(g) For a given characteristic impedance, Z0 and dielectric constant $r$, the $\mathrm{W} / \mathrm{d}$ ratio can be calculated as: [2]

$$
\frac{W}{d}=\left\{\begin{array}{lr}
\frac{8 e^{A}}{e^{2 A}-2} & \text { for } W / d<2 \\
\frac{2}{\pi}\left[B-1-\ln (2 B-1)+\frac{\epsilon_{r}-1}{2 \epsilon_{r}}\left\{\ln (B-1)+0.39-\frac{0.61}{\epsilon_{r}}\right\}\right] & \text { for } W / d>2
\end{array}\right.
$$

\section{DESIGN OF YAGI- UDA ANTENNA}

Yagi-Uda array of four element i.e. one reflector, one driven element and directors. The first vertical element represent reflector, second vertical element represent driven element and rest vertical elements represent adjacent directors. The boom likes rod represents spacing between vertical elements. The input port is used at the feeding point. Physical dimension of Yagi Uda design is shown in table 1 [4].

\section{Table 1: Physical Dimension [4]}

\begin{tabular}{|c|c|}
\hline Reflector & $0.5 \chi$ \\
\hline Driven element & $0.47 \chi$ \\
\hline Directors & $0.406 \lambda$ \\
\hline $\begin{array}{c}\text { Spacing between reflector and driven } \\
\text { element }\end{array}$ & $0.25 \lambda$ \\
\hline $\begin{array}{c}\text { Spacing between driven element and } \\
\text { adjacent directors }\end{array}$ & $0.34 \lambda$ \\
\hline
\end{tabular}

For designing the antenna and we need the value of effective length. We get the value of the effective length by using the physical dimension in the formula:

$\mathrm{E}_{\mathrm{eff}}=\beta \mathrm{L}$ where $\beta=2 \pi / \lambda$

Table 2: Width and length calculation

\begin{tabular}{|c|c|c|}
\hline Elements & width & Length \\
\hline Reflector & $3.80228 \mathrm{~mm}$ & $38.9619 \mathrm{~mm}$ \\
\hline Driven Element & $3.80228 \mathrm{~mm}$ & $36.6242 \mathrm{~mm}$ \\
\hline Director & $3.80228 \mathrm{~mm}$ & $31.6371 \mathrm{~mm}$ \\
\hline $\begin{array}{c}\text { Spacing between reflector and } \\
\text { driven element }\end{array}$ & $3.80228 \mathrm{~mm}$ & $19.4810 \mathrm{~mm}$ \\
\hline $\begin{array}{c}\text { Spacing between driven } \\
\text { element and directors }\end{array}$ & $3.80228 \mathrm{~mm}$ & $26.4941 \mathrm{~mm}$ \\
\hline
\end{tabular}

This Table 2 showing the width and length calculation of the Yagi-Uda antenna after using the formula as per given in equation (1). But the outcomes of this design were not desired for implementations. After several optimizations we got the approximate results. Here we have shown only 2 optimized designs as per our concern.

\subsection{Optimized Design 1}

Designed of 5 element array including a reflector, a feeder element and 3 directors[1], [2], [4] and[6]. The dimension of table are optimized and changes are reflected in table 3 . In this designed we have increased only length of reflector ,driven element and all adjacent director element by $1 \mathrm{~mm}$ and keeping the same dimension of spacing as shown in table 3. we got the $-10 \mathrm{db}$ at $2.45 \mathrm{GHz}$. The designed is simulated in layout window using ADS tool as shon in figure 2.

Table 3: Optimized Design 1

\begin{tabular}{|c|c|c|}
\hline Elements & width & Length \\
\hline Reflector & $3.80228 \mathrm{~mm}$ & $39.9619 \mathrm{~mm}$ \\
\hline Driven Element & $3.80228 \mathrm{~mm}$ & $37.6242 \mathrm{~mm}$ \\
\hline 3 Adjacent Directors & $3.80228 \mathrm{~mm}$ & $32.6371 \mathrm{~mm}$ \\
\hline $\begin{array}{c}\text { Spacing between reflector and } \\
\text { driven element }\end{array}$ & $3.80228 \mathrm{~mm}$ & $19.4810 \mathrm{~mm}$ \\
\hline $\begin{array}{c}\text { Spacing between driven } \\
\text { element and directors }\end{array}$ & $3.80228 \mathrm{~mm}$ & $26.4941 \mathrm{~mm}$ \\
\hline
\end{tabular}

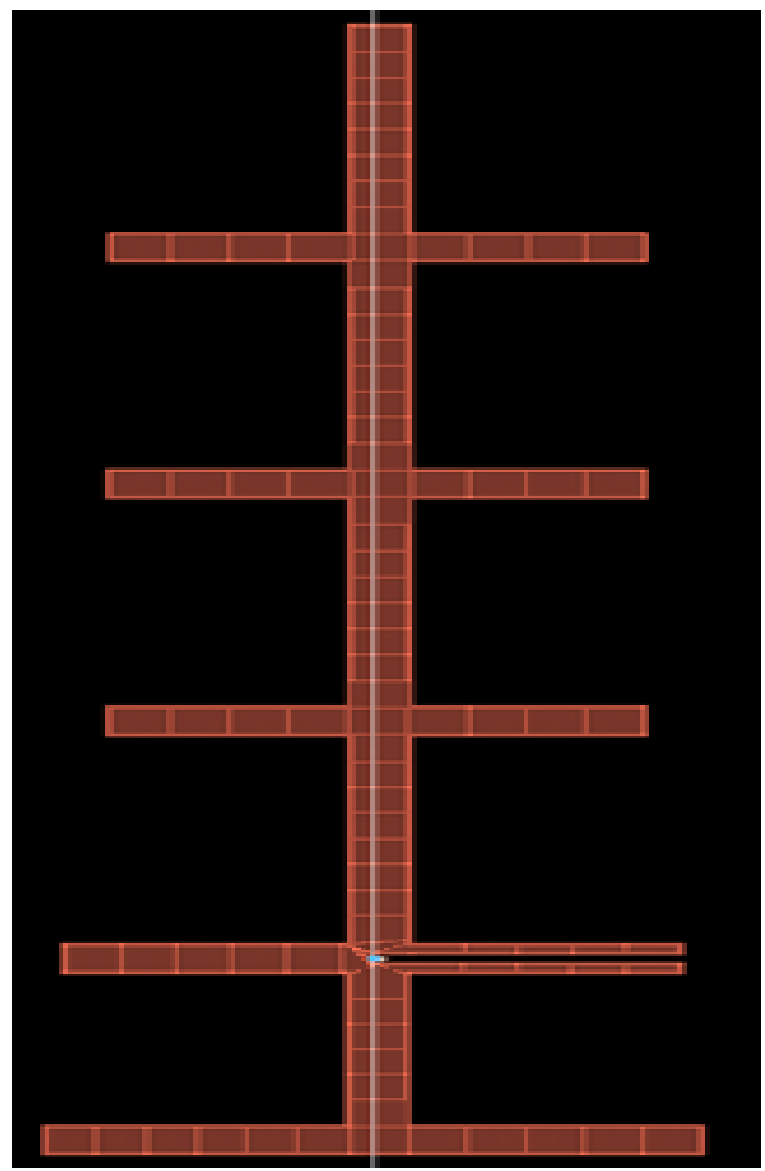

Figure 2: Optimized design 1 of Yagi Uda Antenna

From antenna parameter of this designed as shown in table 3 we concluded that power radiated by five elements Yagi-Uda antenna is $0.104 \mathrm{~mW}$ and gain is $1.36435 \mathrm{~dB}$. The radiated power and gain is not appropriate for designing the antenna but we got desired directivity. 
Table 4: Antenna parameter of optimized design 1

\begin{tabular}{|c|c|}
\hline Power radiated (watts) & 0.000104254 \\
\hline Effective angle(steradians) & 2.78926 \\
\hline Directivity(dB) & 6.53722 \\
\hline Gain(dB) & 1.36435 \\
\hline
\end{tabular}

The input-output relationship between ports in an electrical system is described by the S-parameters. $S_{11}$ is referred to as the reflected power. It must be noted that $\mathrm{S}$-parameters are a function of frequency practically; the most common parameter used in antennas is S11. S11 refers to the amount of power that reflected from the antenna, and therefore, it is called the reflection coefficient denoted by gamma, $\Gamma$ i.e. return loss this received power is either radiated or absorbed as losses within the antenna. As antennas are specifically designed to have a low loss, therefore, the majority of the power delivered to the antenna is radiated. Input return loss is expressed in decibels and is given by [5]:

$\mathrm{RL}_{\text {in }}=-20 \log \left|\mathrm{S}_{11}\right| \mathrm{dB}$

The return loss of optimized design 1 is found to be $-9.5 \mathrm{~dB}$ as shown in figure 3 . The percentage of reflected power can be found by using equation 2 i.e. $33 \%$.

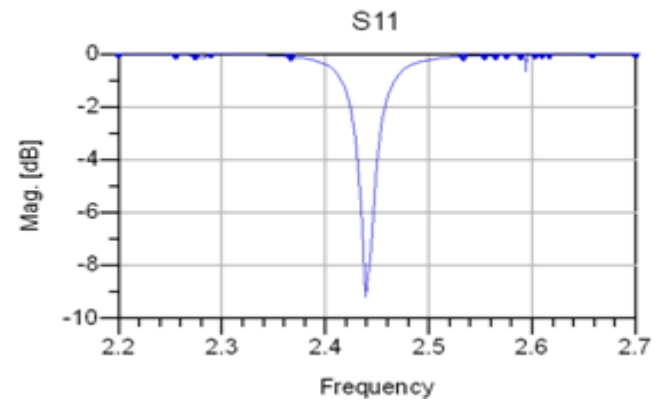

Figure 3: Return Loss of optimized design 1

\subsection{Optimized design 2}

The optimized design of Yagi-Uda antenna is realized by changing the length and spacing of reflector, driven element or feeding element and directors as given below in figure 6 [1], [4] and [6]. In this design, we have increase the length and spacing of each element by $1 \mathrm{~mm}$ as shown in table 5 . After simulation this give the most accurate result near $2.41 \mathrm{GHz}$ frequency with increased in return loss $-12 \mathrm{db}$.

Table 5: Optimized design 2

\begin{tabular}{|c|c|c|}
\hline Elements & width & Length \\
\hline Reflector & $3.80228 \mathrm{~mm}$ & $39.9619 \mathrm{~mm}$ \\
\hline Driven Element & $3.80228 \mathrm{~mm}$ & $37.6242 \mathrm{~mm}$ \\
\hline 2 adjacent Directors & $3.80228 \mathrm{~mm}$ & $32.6371 \mathrm{~mm}$ \\
\hline $\begin{array}{c}\text { Spacing between reflector and } \\
\text { driven element }\end{array}$ & $3.80228 \mathrm{~mm}$ & $20.4810 \mathrm{~mm}$ \\
\hline $\begin{array}{c}\text { Spacing between driven } \\
\text { element and directors }\end{array}$ & $3.80228 \mathrm{~mm}$ & $27.4941 \mathrm{~mm}$ \\
\hline
\end{tabular}

Antenna parameter for the optimized design is shown in table 6 . We concluded that power radiated by five element YagiUda antenna is $15 \mathrm{~mW}$ and gain is $6.18998 \mathrm{~dB}$. The radiated power and gain is improved to a much extent which is appropriate for designing the antenna.

Table 6: Antenna parameter of optimized design 2

\begin{tabular}{|c|c|}
\hline Power radiated (watts) & 0.0156081 \\
\hline Effective angle(steradians) & 2.78119 \\
\hline Directivity(dB) & 6.54979 \\
\hline Gain(dB) & 6.18998 \\
\hline
\end{tabular}

Return loss of optimized design 2 is $-11 \mathrm{~dB}$ shown in figure 4.the percentage of reflected power is calculated from equation 2 is $28 \%$.

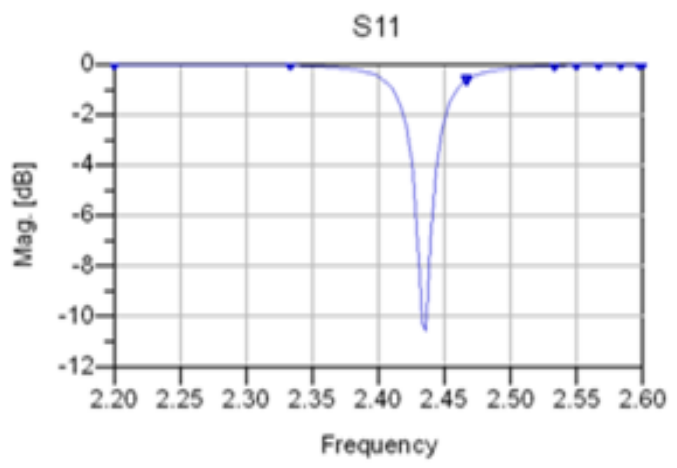

Figure 4: Return Loss of optimized design 2

\subsection{Radiation pattern}

It is observed that radiation pattern of Yagi-Uda optimized design 2 is omnidirectional in pattern as shown on figure 5 . Due to its omnidirectional behavior it can be used in cellular communication system.

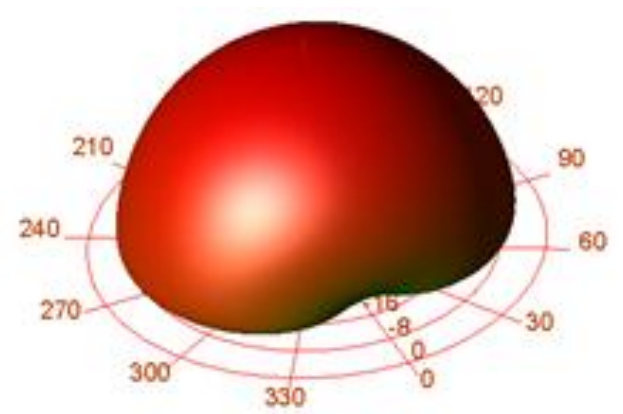

Figure 5: Radiation Pattern 


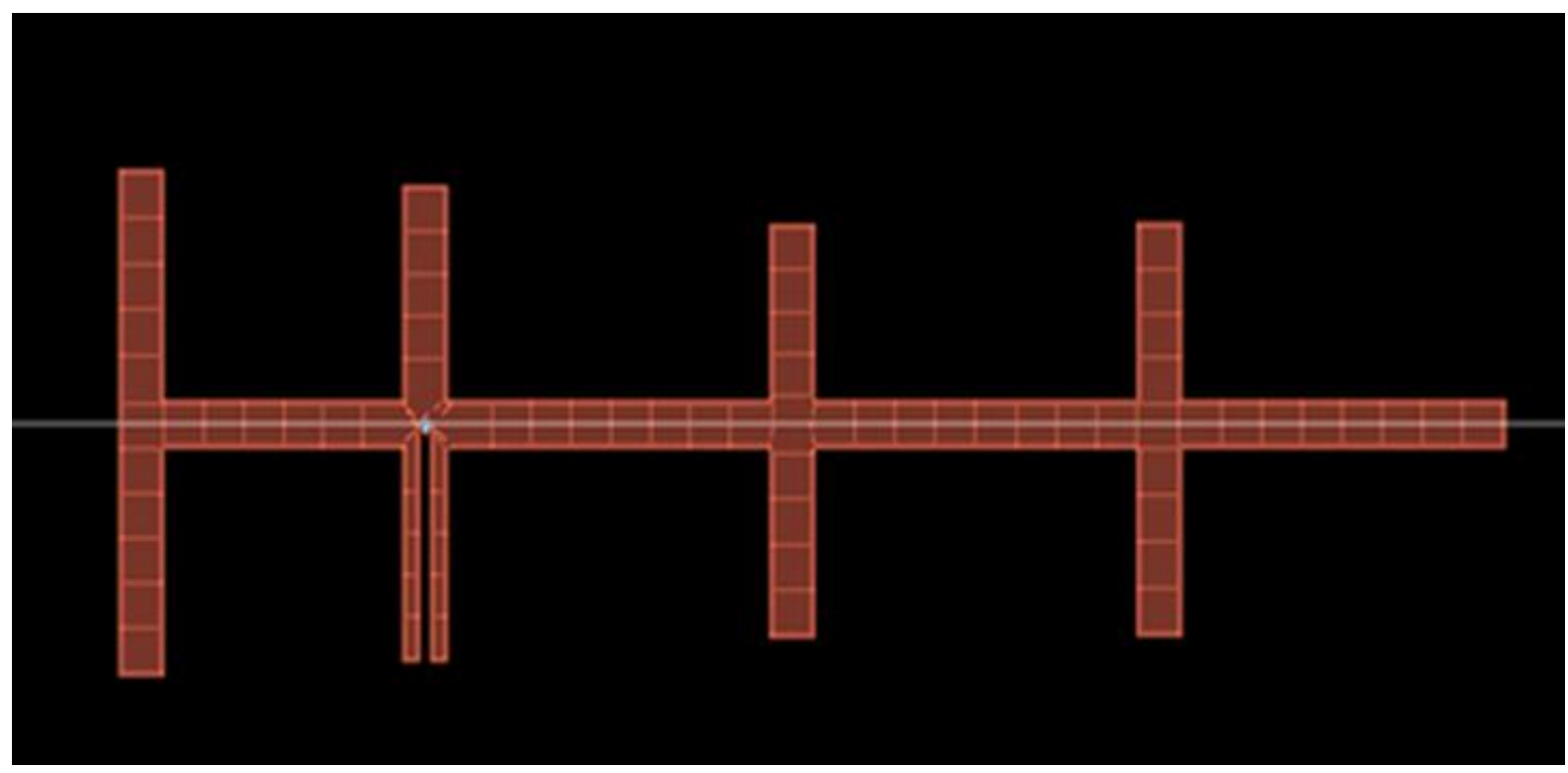

Figure 6: Optimized design 2 of Yagi Uda Antenna

\section{RESULTS AND DISCUSSIONS}

The Simulated result of optimized designed 2 of Yagi-Uda antenna is obtained nearly at the resonant frequency of 2.4 $\mathrm{GHz}$. The return loss of optimized design 1 is found to be $9.5 \mathrm{~dB}$. The percentage of reflected power is $33 \%$ Whereas Return loss of optimized design 2 is $-11 \mathrm{~dB}$ as shown in fig 2 . And $28 \%$ of power is reflected to input port and $72 \%$ of power is radiated. The Power radiated for the optimized design 2 is $15 \mathrm{~mW}$ which is suitable for Yagi-Uda application in cellular mobile communication further can be used for $4 \mathrm{G}$ system. Hence, optimized design 2 of Yagi-Uda antenna can be used in cellular system

\section{CONCLUSIONS}

The Yagi-Uda antenna design is used for the ISM band applications. The main aim of designing this antenna is for cellular mobile communications. Yagi-Uda antenna has very good characteristics such as impedance matching devices, good directivity and gain. As Yagi-Uda antenna has a big size, we cannot implement it in cellular communications. So instead of implementing it with conducting wires; we implemented this antenna using microstrip circuit whose dimension is found to be in $\mathrm{mm}$ range. Microstrip circuits have several advantages. It is compatible with the microwave active devices that can be very easily mounted on the substrate. It has resulted into enormous reduction in volume and weight, increase in reliability, reduction in cost and mass production. Applications of microstrip circuits are in radar systems, microwave communication links, satellite communication systems, wireless and mobile communication systems, medical equipment, etc.

\section{ACKNOWLEDGMENTS}

The author would like to thanks to mentor of this project, R. Madhusudhan Goud for the valuable guidance and advice. He inspired us greatly to work in this project. I also would like to thank him for showing some example that related to the topic of project. We would like to acknowledge the Dean and Head of the Department, Electronics and Communication Engineering, Lovely Professional University, Phagwara (Jalandhar) for providing project facility and valuable suggestion for this work

\section{REFERENCES}

[1] Satyandra Singh Lodhi, P.K.Singhal, V.V.Thakre, Govind Singh Thakur, "Design of microstripYagi- Uda antenna with three parasitic elements at $2.54 \mathrm{GHz}$,"Progress in antenna designing designing research, Vol. 01, 80- 84, 2013.

[2] Kavita Nayak 1, D.K. Srivastava 2, J. Kavita NP Saini "Yagi Microstrip Patch Antenna for GPS and Mobile Communication".

[3] AnkitAgnihotri ,AkshayPrabhu,Dheerendra Mishra B.tech (EC), Kanpur Institute of Technology, A-1 UPSIDC, Industrial Area, Rooma, Kanpur (U.P.) (affiliated to GBTU University, Lucknow), India

[4] Antenna theory Analysis and design, $3^{\text {rd }}$ wilay India edition by Constantine A. Balanis

[5] Microwave Engineering $4^{\text {th }}$ edition by David M. Pojar University of Massachusetts at Amherst

[6] Antenna for all application $3^{\text {rd }}$ edition by John D Kraus. 